\title{
Historia de las Luchas por la Justicia Ambiental en las Zonas de Sacrificio en Chile
}

Paola Bolados García ${ }^{1}$, Valeska Morales Urbina ${ }^{2}$, Stephanie Barraza López ${ }^{3}$

\section{RESUMEN}

En este artículo analizamos la historia ambiental de tres bahías costeras denominadas como zonas de sacrificio en Chile. Desde sus historias marcadas por las desigualdades socioambientales y la lucha por justicia ambiental, observamos el proceso de conflictividad social y ambiental incorporando los aportes de la historia ambiental, la ecología política de los extractivismos y la geografía crítica, dando cuenta de las estrategias comunitarias y organizativas que buscan recuperar social y ambientalmente estos territorios degradados. Concluimos, que en este proceso el concepto de justicia ambiental adquiere lecturas menos jurídicas y más socio ambientales a través experiencias colectivas que toman como centro la recuperación de los ecosistemas desde la participación comunitaria y la memoria.

Palabras clave: Desigualdades Socioambientales; Justicia Ambiental; Extractivismo; Recuperación Socioambiental.

\footnotetext{
1 Doctora Investigadora (Centro de Estudios Avanzados). Académica de la Facultad de Ciencias Sociales. Observatorio de Participación Social y Territorio de la Universidad de Playa Ancha. ORCID: https://orcid.org/0000-0002-1583-007X. e-mail: paola.bolados@upla.cl

2 Doctoranda en Sociología y magister en investigación educativa (Universidad Autónoma de Barcelona). ORCID: https://orcid.org/0000-0003-0431-8465. e-mail: v.morales.urbina@gmail.com

${ }_{3}^{3}$ Magister en Investigación Social y Desarrollo (Universidad de Concepción). ORCID: https://orcid.org/0000-0001-7607-1911. Email: stephanibarraza@udec.cl
} 


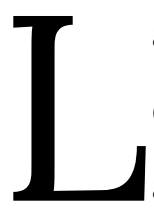

a categoría "zonas de sacrificio" adquiere particular protagonismo en la última década a propósito de los múltiples desastres ambientales provocados por actividades contaminantes y peligrosas en comunidades y organizaciones de América Latina. Éstas, frente al daño de sus territorios, han articulado movilizaciones que claman por justicia ambiental y problematizan respecto a los alcances y limitaciones de un crecimiento sin desarrollo, que bajo diversas retóricas nacionalistas o transnacionales, han destinado sus espacios vitales a una destrucción sostenida.

En Chile, este proceso se acelera en el último tercio del siglo $\mathrm{XX}$, con la arquitectura legal de la dictadura cívico-militar en los años 80, el cual se intensificó con el retorno a la democracia y sus gobiernos de centro-izquierda. La profundización de la economía extractivista se observó con mayor claridad, una vez instauradas las legislaciones indígenas y ambientales de los años 90, que no significaron un cambio en las bases instauradas por el régimen militar. Estas más bien se subordinan a la lógica privatista de la constitución y su consagración en los códigos de agua y minero de los años 81 y 82, que destinaron el uso intensivo de los bienes naturales para las actividades mineras, agrícolas, forestales, energéticas, etcétera.

En ese marco, se intensificó la instalación de polos industriales contaminantes en la década de los años 90, los cuales buscaron consolidar visiones neoliberales en zonas donde se emplazaron proyectos de corte desarrollistas en la década de los 60. Bajo idearios industrializadores, en los años 90, se refuerza la visión sobre estos territorios como espacios dispuestos para ser cuenca de soporte de diversos extractivismos y sede de nuevos proyectos e inversiones. La política de apertura económica en Chile, tendrá como característica la firma de tratados de libre comercio, los cuales centraron su interés en los mercados del sudeste asiático, quienes lideraron la demanda de commodities mineros durante estas décadas. De esta forma, se refuerza el imaginario portuario del país como un corredor bioceánico clave para la entrada y salida de materias primas en y hacia América Latina.

La reprimarización de la economía y la intensificación de la actividad exportadora a nivel latinoamericano, tuvieron como escenario algunas iniciativas 
regionales como el IIRSA liderados por países en la era progresista vinculados al UNASUR (Proyecto de mega-infraestructura). Estos intensificaron la actividad asociada a expansión de puertos, corredores, ferrocarriles, etc.; cuyas actividades fueron generando cada vez más conflictos con las comunidades y territorios que se vieron afectados en su calidad de vida. En las últimas dos décadas se emplazaron megaproyectos hidroeléctricos en Brasil, se desarrollaron nuevos sistemas de explotación en torno al sistema fracking en Argentina, y en Chile se produce un boom de commodities mineros, pesqueros, agrícolas y forestales. En particular, Chile durante estas décadas lideró la exportación de cobre y litio, intensificando conflictos asociados a la contaminación, pérdida de glaciares y una de las crisis hídricas más prolongadas de los últimos cien años. En Paraguay, el ejemplo de Villa Hayes representa un caso similar donde la concentración de empresas y por ende de contaminación, apoyados por débiles normativas y desregulados o inexistentes instrumentos de planificación territorial, habilitan la construcción y expansión de complejos minero-energéticos, forestales, pesqueros, transformando estos territorios en zonas de sacrificio. ${ }^{4}$

Detrás de la denominación algunos autores ven una lógica neodesarrollista impuesta desde las décadas de los 50, que refuerza un destino y naturaliza una supuesta "vocación" o ventaja comparativa dentro de una perspectiva económica neoliberal asociada a alguna actividad extractiva. Con esta lógica, los intereses de los territorios y sus habitantes son subalternizados bajo imaginarios de desarrollo nacional, invisibilizando gran parte de las veces la naturaleza transnacional de estos complejos, y promoviendo la especialización de los territorios bajo los idearios de "región minera", "región agroexportadora", "región forestal, "región salmonera". Estas "vocaciones territoriales" dan cuenta no solo de las desigualdades económicas y ecológicas que se perpetúan, sino también el papel que estas zonas cumplen en el mapa geopolítico y económico actual. ${ }^{5}$

\footnotetext{
4 Lida Tellez, Leo Name y Céline Veríssimo, "Injusticia ambiental en un contexto industrial: el caso de Villa Hayes (Paraguay) como zona de sacrificio," (paper presentada en XVI Encuentro de Geógrafos de América Latina, La Paz, Bolivia, 2017), http://observatoriogeograficoamericalatina.org.mx/egal16/Procesosambientales/Climatologia/32.pdf.

${ }^{5}$ Andrés Nuñez y Enrique Aliste, Geografías imaginarias y el oasis del desarrollo: Cambio Climático y la promesa del futuro esplendor (Santiago, Chile: LOM, 2020), p. 29.
} 
Las desigualdades en términos de las cargas del daño ambiental concentrados en ciertos territorios, se condicen con desigualdades que refieren a la pérdida del acceso a los recursos y bienes naturales históricos, perjudicando las economías y oficios tradicionales, que ocasionan problemas sociales y a la salud, producto del empobrecimiento de estas comunidades. En ese contexto, y transcurrida las primeras épocas de denuncia de las afectaciones a la salud, las comunidades perjudicadas profundizan en las valoraciones ecológicas de sus territorios, encontrando en ellas formas para recuperarse de manera multidimensional.

Desde una revisión de la literatura y de entrevistas a actores territoriales de tres bahías puertos consideradas como zonas de sacrificio en el norte, centro y sur de Chile, en este artículo damos cuenta de las experiencias de luchas y resistencias que estos territorios y comunidades despliegan, a fin de contestar la categoría mostrando sus dimensiones de agencia y visibilizando las prácticas de justicia ambiental que éstas despliegan en sus territorios.

LAS ZONAS DE SACRIFICIO COMO LUGAR DE EXTREMAS DESIGUALDADES. UNA MIRADA DESDE LA Ecología Política y la Historia AMBiental latinOAMERICANA

Conscientes del daño en sus territorios, comunidades y organizaciones relacionan la causa de los desastres ecológicos con las desigualdades socioambientales legitimadas por las limitaciones e ineficacias de la legislación ambiental. ${ }^{6}$ A su vez, profundizan desde sus historias ambientales la comprensión de la noción de justicia ambiental, más allá del campo jurídico propiamente tal, planteando otros modos de comprender la interdependencia sociedad y naturaleza. Esta relación implica reconocer diversas valoraciones y cosmovisiones sobre la naturaleza y el medio ambiente fuera del campo extractivista, productivista y mercantilista. Por el contrario, esta visión impuesta como la única posible, comienza a ser cuestionada por los habitantes que ven modificar su paisaje, su estructura social y comunitaria, y sus economías.

\footnotetext{
6 Pedro Villasana López et al., "Zonas De Sacrificio Y Justicia Ambiental En Chile. Una Mirada Crítica Desde Los Objetivos De Desarrollo Sostenible 2030," Historia Ambiental Latinoamericana Y Caribeña (HALAC) Revista De La Solcha 10, no. 3 (Diciembre 2020): 342-65, doi:10.32991/2237-2717.2020v10i3.
} 
En este contexto, la categoría zonas de sacrificio precisa comprenderse como un concepto explicativo de las extremas desigualdades sociales y ambientales concentradas en algunos territorios. Un concepto que precisa ser analizado de manera multidimensional e interdisciplinar en el contexto de la actual crisis ecológica y sanitaria. Esto nos desafía a revisar las contribuciones sustanciales de la Ecología Política y la Historia Ambiental Latinoamericana, así como también los aportes de la geografía crítica y la justicia ambiental en la configuración de las desigualdades socioambientales de la época reciente. Como sostiene Alimonda, sin atender a la "persistente colonialidad que afecta a la naturaleza latinoamericana" ni "mirar la primera modernidad que vio a América como su primera periferia y legitimó una geopolítica epistemológica (antropo-etno y eurocentrista), resulta imposible de comprender "nuestra incorporación subordinada a la modernidad" a través del término progreso y desarrollo. ${ }^{7}$

La intensificación del extractivismo en la región caracterizado por el boom de los commodities mineros, agroexportadores, pesqueros, forestales y energéticos fueron descritos como el paso del consenso de Washington al consenso de Beijing, donde la demanda China generó una presión mayor sobre territorios donde se concentran los bienes comunes naturales requeridos por estos extractivismos. En otros casos, se trata de espacios geográficos ratificados como cuencas de soporte de estos extractivismos cuyas actividades tóxicas y peligrosas dañaron progresivamente las condiciones ecológicas y bioculturales ${ }^{8}$. Las desigualdades ambientales en términos de las cargas que algunos territorios sobrellevan en sus hombros, corren paralelas a las desigualdades sociales que significa la relegación social y exclusión de los mecanismos de participación en las decisiones que dañan sus territorios. ${ }^{9}$

Las zonas de sacrificio en Chile son lugares donde se concentran las afectaciones producidas por los requerimientos energéticos de la actividad extractiva. Algunas asociadas a actividades mineras como refinerías y fundiciones de cobre o

\footnotetext{
7 Hector Alimonda, "La colonialidad de la naturaleza. Una aproximación a la Ecología Política Latinoamericana," en La Naturaleza Colonizada. Cord. por Hector Alimonda (Argentina: CLACSO, 2011), p. 24.

${ }^{8}$ Eduardo Gudynas, Extractivismos. Ecología y política de un modo de entender el desarrollo y la naturaleza, (Perú: CLAES, 2015), p. 151.

9Gabriela Merlisnky, Política, derechos y justicia ambiental: El conflicto del Riachuelo, (Argentina: Fondo Cultura Económica, 2013), p. 31.
} 
hierro, y otras vinculadas a la instalación de termoeléctricas basadas en fósiles como petróleo, carbón y petcoke. En otros casos, asociada a actividades forestales que instalan sus celulosas y pesqueras, cuyas actividades de procesamiento generan olores que afectan la calidad de vida y salud de las y los habitantes. Tras promesas de empleo y desarrollo, a un par de décadas transcurridas sus instalaciones, desde los años 90 se ha comenzado a evidenciar el daño a los ecosistemas, de las economías por la pérdida de los bienes naturales y oficios tradicionales y finalmente, la afectación a la salud que generan preocupación, alarma y resistencias entre las organizaciones y sectores de la comunidad afectados. Como sostiene Merlinsky:

[...] los efectos de los peligros ambientales se acumulan en períodos que duran décadas y suelen ser invisibles (viajan bajo tierra en conductos cloacales o emisarios industriales, están difundidos en partículas en el aire o drenan contaminantes en el suelo y los cursos de agua). Por eso cuando los ciudadanos toman cuenta de ellos es porque han aparecido las primera manifestaciones en la salud de las personas. ${ }^{10}$

La naturaleza colonizada logra mercantilizarse mediante una desposesión legitimada por una ciencia y una hegemonía tecnológica que piensa las soluciones a la naturaleza desde una visión económica. ${ }^{11}$ Una racionalidad científico-técnica que fractura la naturaleza, dividiendo la integralidad del territorio y las experiencias de comunidades y organizaciones sobre su propio lugar ${ }^{12}$. Conocimientos y racionalidad que implicó una negación de los saberes populares de la naturaleza y el rechazo a los conocimientos indígenas basados en lo colectivo y la ritualidad cotidiana. Estos procesos en los años 90 Svampa los refiere como el giro ecoterritorial ${ }^{13}$, en tanto la protección del territorio articula procesos donde confluyen organizaciones ambientales, indígenas y grupos urbanos que luchan contra el extractivismo y su explotación intensiva de la naturaleza. La naturaleza objetivada por la ciencia, comienza así un proceso de desnaturalización de los argumentos que favorecen su explotación irracional e instauran una nueva racionalidad ecológica. ${ }^{14}$

\footnotetext{
10Merlinsky. Política, derechos y justicia ambienta...: p. 31.

${ }^{11}$ Arturo Escobar, "Ecología Política de la globalidad y la diferencia" en La Naturaleza Colonizada. Coord. Alimonda H. (Argentina, CLACSO, 2005): p. 17.

12Enrique Leff, "La ecología política en América Latina: Un campo en construcción," Sociedad y Estado 18, n 1/2(Sept. 2003 ): p. 19. 13Maristella Svampa y Ariel Slipak, "China en América Latina: Del Consenso de los Commodities al Consenso de Beijing," Ensambles 2, no. 3 (Primavera 2015): p. 188.

14Leff , "La ecología política...", (2003):p. 22.
} 
Como sostiene Escobar "esta reivindicación no reclama una esencia étnica ni derechos fincados en el principio jurídico y metafísico del individuo, sino en el derecho del ser, que incluye tanto los valores intrínsecos de la naturaleza como los derechos humanos diferenciados culturalmente, incluyendo el derecho a disentir de los sentidos preestablecidos y legitimados por poderes hegemónicos" ${ }^{15}$ Converge la filosofía del buen vivir con una visión ecológica, de respeto del medioambiente. La defensa del territorio como hábitat y comunidad de vida, se constituye en el punto de partida de los reclamos de las movilizaciones y movimientos campesinos, indígenas, así como de los nuevos movimientos socio-territoriales. ${ }^{16}$

JUSTICIA AMBIENTAL Y ZONAS DE SACRIFICIO. ¿DOS CARAS DE LA MISMA MONEDA O DOS MONEDAS DE LA MISMA CARA?

El concepto de zonas de sacrificio introducido en Chile hacia el 2010 por organizaciones no gubernamentales y fundaciones ambientales como TERRAM, OCEANA, etc.; es heredero del movimiento de justicia ambiental norteamericano relevado por Lerner en la década de los años $80 .{ }^{17} \mathrm{El}$ movimiento de la justicia ambiental reconoce sus orígenes asociados a una población afroamericana de la localidad de Warren en el Estado de Carolina del Norte en Estados Unidos, localidad expuesta a nocivos riesgos generados por un vertedero de residuos tóxicos, a partir del cual se utiliza por primera vez el concepto de racismo ambiental. ${ }^{18}$ Bullard narra esta historia de lucha, incorporando la noción de la justicia ambiental. Esta perspectiva se afirma en la tesis de que "los factores de raza como de clase ponen a las comunidades de bajos ingresos y de personas de color en riesgo."19

El 1996 se realizó la primera reunión nacional llamada First National People of Color Environmental Leadership de los grupos de justicia ambiental, que reunió a 650 activistas de EEUU y algunos otros líderes de movimientos en el extranjero. Es importante recordar este momento, ya que a partir de esta reunión se crean los 17

\footnotetext{
15 Escobar, "Ecología Política de la globalidad y la diferencia...," p. 61-92.

${ }^{16}$ Svampa y Slipak, "China en América Latina...":p. 190.

17 Steve Lerner, Sacrifice Zones: The Front Lines of Toxic Chemical Exposure in the United States (Cambrige-Massachusets: MIT Press 2010), p. 8.

18 Miquel Ortega, "Origen y Evolución del movimiento de la Justicia Ambiental" Ecología política, no. 41 (Junio 18, 2011 ): p. 18.

19 Robert Bullard, Dumping in Dixie: Race, class, and environmental quality, 3 ed. (New York, NY: Routledge, 2018), p. 135.
} 
principios sobre la justicia ambiental, los cuales expresan los primeros lineamientos con lo que se define la misma. Dentro de estos principios se destaca la relación de la sociedad con la naturaleza, expresando lo sagrado de la tierra, la interdependencia de las especies y el derecho de no sufrir destrucciones ecológicas, reclamando el uso étnico, equilibrado y responsable de los recursos renovables. ${ }^{20}$

En los principios de la Justicia Ambiental no sólo se habla de racismo ambiental, sino que también de la injusticia en la salud, el trabajo, el uso de la tierra, es decir, apunta a expandirse hacia una perspectiva internacional. ${ }^{21} \mathrm{~A}$ modo de contribuir el aspecto distributivo de la justicia ambiental, Schloberg plantea que es importante agregar el componente de reconocimiento al concepto de Justicia Ambiental, ya que considera que las localidades altamente vulnerables y desfavorecidas a nivel ambiental son escasamente conocidas y valoradas, lo que incrementa el grado de injusticia. ${ }^{22} \mathrm{En}$ consecuencia, la falta de reconocimiento promueve una exclusión sistemática de la comunidad, debido a que las comunidades no son invitadas a participar en los espacios de decisiones políticas que afectan su territorio y su vida. Los aspectos procedimentales, centrales en la justicia ambiental, se basan en el acceso justo y equitativo en la toma de decisiones y en los recursos en derecho medioambiental. ${ }^{23}$ En la justicia ambiental como un concepto procesal, el Estado tiene el rol de facilitar ayuda para que las y los ciudadanos puedan informarse sobre los proyectos, éste debe proveer experiencia técnica, legal, evitando así una desinformación en los grupos de baja situación económica, que carecen de asesoramiento jurídico y técnico. ${ }^{24}$

Las demandas de las comunidades afectadas son invisibilizadas por parte de los Estados, es por esto que estos movimientos buscan hacer oír sus voces a través de prácticas como protestas, bloqueos, ocupaciones, manifestaciones artísticas, narrativas sobre la defensa del agua, los ríos y los bosques, con el fin de generar estrategias para articularse a nivel internacional con los movimientos que luchan por

\footnotetext{
20 Ejnet.org Editors, "Principles of Environmental Justice," April 6, 1996, http://www.ejnet.org/ej/principles.html

21 Ortega,"Origen y Evolución del movimiento...”:p. 19.

22 David Schlosberg, "Justicia ambiental y climática: de la equidad al funcionamiento comunitario," Ecología política, no. 41 (Junio 18, 2011): p. 34.

${ }^{23}$ Alicia Arriaga y Mercedes Pardo, "Justicia Ambiental: El estado de la cuestión," Revista Internacional de Sociología 69, no. 3 (Diciembre 2011): p. 642, doi: 10.3989/ris.2009.12.210

${ }^{24}$ Sherrie Baver, "Institutions of Environmental Democracy and Environmental Justice: The Case of Chile," CUNY Graduate Center, no. 554 (April, 2017): p. 2-3.
} 
la justicia ambiental. ${ }^{25}$ Los activistas de la Justicia Ambiental exigen una formulación de las políticas para que éstas fomenten la participación de la comunidad, incorporando de esta manera un reconocimiento de la comunidad y de los intercambios interculturales. Estos grupos piden "un lugar en la mesa" y el derecho de hablar por ellos mismos. ${ }^{26}$

La propuesta de justicia ambiental distributiva, basado en lo que propone Martínez Alier ${ }^{27}$ puede relacionarse con la discusión que plantea Agoglia, sobre la relación de la ecología política y la justicia ambiental, donde se puede generar una relación entre los aspectos distributivos y de apropiación, incorporados por los distintos enfoques de la ecología política, poniendo como principio el problema de la apropiación. ${ }^{28}$ Esto se relaciona con la preocupación de Schlosberg, quien dice que "cualquier análisis de justicia requiere que se discutan las estructuras, las prácticas, las reglas, las normas, el lenguaje y los símbolos que actúan como mediadores de las relaciones sociales"29, lo cual no significa dejar de lado los factores distributivos, sino más bien ampliar esta interpretación para poner atención sobre "cómo hemos llegado dónde estamos". La preocupación por el principio de la desigual distribución converge de manera más cercana al enfoque materialista de Alimonda. Tal como lo dice Schlosberg, si en los análisis de la justicia ambiental se discuten aspectos simbólicos y de lenguaje con respecto a las relaciones sociales (y de poder), se podría generar una vinculación más profunda con la propuesta de Agoglia, de conectar el pensamiento crítico Latinoamericano con el de la ecología política. ${ }^{30}$

Una de las características particulares que tiene la justicia ambiental es que aglutina todas las luchas de los grupos sociales ambientalmente desfavorecidos, ya sea urbana, rurales, del norte o del sur con el fin de obtener el derecho de vivir en un

\footnotetext{
${ }^{25}$ Echart Muñoz y María del Carmen Villarreal, "Resistencias y alternativas al desarrollo en América Latina y el Caribe: luchas sociales contra el extractivismo," Revista Relaciones Internacionales, no. 39 (Agosto 2018): p. 145, doi:10.15366/relacionesinternaciona-les2018.39.001

26 David Schloberg, "Reconceiving Environmental Justice: Global Movements And Political Theories," Environmental Politics 13, no. 3 (mes 2004): p. 522-523, doi:0.1080/0964401042000229025

27 Joan Martínez Alier, "Ecologismo de los Pobres," Ecologistas en Acción (Septiembre 1, 2015), https://www.ecologistasenaccion.org/7976/el-ecologismo-de-los-pobres/.

28 Ofelia Agoglia, "Los aportes de la ecología política latinoamericana a la corriente ambiental crítica," América Crítica 2, no. 2 (Diciembre 2018): p. 116-117, doi:10.13125/americacritica/3306

29 Schlosberg, "Justicia ambiental y climática...": p. 27.

30 Agoglia, "Los aportes de la ecología política latinoamericana...": p. 117-118,
} 
lugar que permita reproducir una vida digna. ${ }^{31}$ Esto ha generado que en los últimos años, la justicia ambiental se posicione como un término en común para producir un cambio estructural a nivel ambiental. ${ }^{32}$ Si bien en algunos casos las luchas por la justicia ambiental está fuertemente ligada a la incidencia en los procesos judiciales, es importante destacar que este movimiento obtiene un carácter político que le entrega una particularidad y una expansión a nivel internacional. El caso de injusticia ambiental que describe Merlinsky en Argentina sobre la cuenca Matanza-Riachuelo, hace referencia a una lucha de organización territorial que tiene el objetivo de reclamar al Estado y a las políticas públicas sobre las acciones y omisiones de los problemas estructurales. ${ }^{33}$

No obstante, el término zonas de sacrificio tuvo una lectura latinoamericana muy temprana y paralela al desarrollado por Lerner. Este fue desarrollado por el brasileño Henry Acselrad ${ }^{34}$, quien recalca dimensiones políticas del término, en tanto estos lugares no se entienden sólo como espacios que cargan con los daños ambientales en nombre del desarrollo nacional, sino se configuran en lugares privilegiados para actividades irregulares de empresas nacionales e internacionales, y sede de actos de corrupción asociadas a ser sede de nuevos proyectos e inversiones, incluso violando leyes y normas ambientales. Desde la crisis ambiental en Río de Janeiro, describe las acciones de lucha ambiental que surgen desde las comunidades pobres, indígenas y afro brasileñas contra quienes amenazan sus modos de vida.

Recientemente en Chile el término viene siendo trabajado por diversos autores que ponen el acento en cómo el término ha sido apropiado y contestado desde los territorios afectados a partir de resistencias de comunidades, en particular de mujeres en contextos de complejos minero-energéticos que denuncian la violencia ambiental que ha dañado los ecosistemas y la salud de sus hijos, padres y en sus

\footnotetext{
31 Mauricio Folchi, "Environmentalism of the Poor: Environmental Conflicts and Environmental Justice," en Social-ecological Systems of Latin America: Complexities and Challenges, ed. Luisa Delgado y Victor Marín (Switzerland: Springer Nature, 2019), p. 110, doi: https://doi.org/10.1007/978-3-030-28452-7

32 Juan David Arias, "Ecología Política: Desafíos de la Contabilidad frente a la Justicia Ambiental," En-contexto, no. 6 (febrero 2017): p. 312.

33 Gabriela Merlinsky, "Justicia Ambiental y políticas de reconocimiento en Buenos Aires," Perfiles Latinoamericanos 26, no. 51 (Enero 2018):p. 256, doi:10.18504/pl2651-010-201

34Henry Acselrad, Conflito social e meio ambiente no estado do Rio de Janeiro (Sao Paulo, Editora Relume Dumará, 2004 ): p. 12.
} 
propios cuerpos..$^{35}$ Otros autores enfatizan las condiciones políticas y jurídicas que facilitan la instalación de estas industrias contaminantes, poniendo énfasis en las insuficiencias legales y normativas. ${ }^{36}$

Un tercer grupo de trabajos dan cuenta de la problemática de salud como un aspecto central de las zonas de sacrificio, mostrando la incoherencia de cumplir con los compromisos internacionales asumidos por Chile, entre ellos, los Objetivos de Desarrollo Sostenible para el 2030, mientras aumenta la evidencia científica respecto al daño a la salud que estas actividades generan en estos territorios. Desde una aproximación que asume las zonas de sacrificio como un concepto en construcción, estos trabajos buscan ampliar la denominación para referirse al desastre ambiental generado por la industria salmonera en el sur de Chile como es el caso del seno de Reloncaví y la isla de Chiloé, las cuales han visto no sólo modificar el paisaje y la estructura laboral de la zona con los efectos dramáticos en la salud mental, sino también la afectación a la salud de las personas y los ecosistemas no cuantificada que genera el excesivo uso de antibióticos en esta industria. ${ }^{37}$

Estos trabajos apuntan a que las afectaciones del extractivismo no sólo repercuten en la salud humana sino también en la salud de la flora, fauna y medio ambiente. Desde una mirada de la ecología humana, estos trabajos recalcan la afectación en la salud mental de las personas y comunidades, especialmente las más vulnerables, transformando sus cotidianidad y generando problemas que interfieren en su bienestar psicológico y social. Se trata de entender la salud como la contracara del concepto de bienestar colectivo, un concepto multidimensional que requiere ser trabajado de manera multidisciplinar y que incluye "aspectos psicológicos, sociales, educativos, espirituales, económicos, ecológicos, ideológicos, históricos y de políticas

\footnotetext{
${ }_{35}$ Paola Bolados y Bárbara Jerez, "Genealogía de un desastre: la historia ambiental de una zona de sacrificio en la bahía de Quintero, Chile," en Pensamento crítico latino-americano, Reflexoes sobre políticas e fronteras, (Belém, Annablume Ediciones, 2019): p. 149-150. Katia Valenzuela et al., "From Resistance to Creation: Socio-Environmental Activism in Chile's "Sacrifice Zones,"'Sustainability 13, no. 6.(Marzo, 2021), doi:10.3390/su13063481

${ }^{36}$ Alejandro Retamal Maldonado et al., "Zonas de sacrificio en Chile, criterios y condiciones de posibilidad: el caso del Seno del Reloncavi". Revista Notas Históricas y Geográficas, no. 26, (Abril 2021): p. 95-143.

Manuel Folchi. "Zonas de sacrificio: Distinto origen, mismo destino," Position Paper N¹, Serie Desastres Socionaturales, Ed. por Enrique Aliste et al., (Santiago, Chile:Universidad de Chile, 2020), p. 29-35.

Andrés Nuñez y Enrique Aliste, Geografias imaginarias y el oasis del desarrollo: Cambio climático y la promesa del futuro esplendor (Santiago, LOM, 2020):p. 29-45.

37 Pedro Villasana et al., "Zonas de sacrificio y justicia ambiental en Chile: una mirada crítica desde los Objetivos de Desarrollo Sostenible 2030," en Historia Ambiental, Latinoamericana y Caribeña 10, no. 3 (Diciembre, 2020): p. 342-365.
} 
públicas, que constituyen parte esencial de la salud de la comunidad y de su calidad de vida". ${ }^{38}$

HistoRia AMBIENTAL Y LUCHAS POR LA JUSTICIA AMBIENTAL: UN RECORRIDO POR HUASCO, Puchuncaví, Quintero y CoRonel.

Estas cuatro comunas fueron consideradas como parte de las seis zonas de sacrificio existentes en Chile, en medio de una intensificación de desastres ambientales que han ocurrido en los últimos años en estas bahías puerto del norte, centro y sur de Chile. Territorios que poseen como común denominador la presencia de numerosas termoeléctricas a carbón y/o petróleo, instaladas varias de ellas en la década de los años 90, y cuyas comunidades iniciaron un proceso de organización lenta y compleja asociada a los permanentes casos de varamientos de carbón, derrames de hidrocarburos y químicos, intoxicaciones de niños y adolescentes, y el surgimiento de numerosos estudios que comienzan a dar a conocer la presencia de metales pesados en peces y mariscos, de los suelos y productos agrícolas, mercurio y otros metales en mujeres y niñas/os. La construcción de estos complejos fue generando progresivamente la pérdida de acceso a los recursos y bienes naturales, y con ello la desaparición de las economías tradicionales locales tales como la pesca artesanal, la agricultura, criancería (crianza de cabras) o la olivocultura (productores de Olivo).

Este proceso tendrá como consecuencia una nueva reestructuración social, la cual forzará a los habitantes a incorporarse directa o indirectamente a las actividades de las empresas. En este contexto, las desigualdades ambientales devienen en desigualdades de género en tanto, las mujeres no sólo quedan excluidas del acceso al empleo en estas empresa en su mayoría, sino sobre ellas recae los impactos de la violencia ambiental y sexual, que sobre determina las asignaciones de género

38 Alex Véliz-Burgos, "Ecología, salud y bienestar humano: miradas desde la Psicología," Revista costarricense de psicología 39, (Abril 2020): p. 1-2. 
relacionadas con la economía de los cuidados de enfermos y niños en un contexto de división social y sexual marcado por el extractivismo. ${ }^{39}$

Si miramos Chile de norte a sur, la primera comuna analizada en este estudio es Huasco, que se ubica en la costa de la provincia homónima, al sur de la región de Atacama. La provincia del Huasco está marcada por un vaivén entre progreso y decadencia minera, acompañado de períodos de crisis políticas y económicas, experimentando por ejemplo el auge de la extracción del mineral de plata y oro en la comuna de Freirina en 1699, y luego entre 1931 y 1960, con el redescubrimiento y explotación de la mina Capote, antiguo yacimiento diaguita y luego Inca, complejo que hoy son ruinas.

Al igual que Coronel y Quintero-Puchuncaví, la comuna de Huasco vivió una inflexión significativa en su historia ambiental a mediados del siglo XX, de acuerdo a Millán ${ }^{40}$ entre octubre de 1953 a 1955, hubo dos hechos que marcaron la línea histórica, "productiva" del Valle del Huasco, por una parte se iniciaron las construcciones de la primera fase del puerto Las Losas y la Planta de Pellets de Compañía de Acero del Pacífico (CAP), y con ello la unión al continente de la isla Guacolda, transformándola en península, hitos reconocidos como símbolo de progreso, que daría cabida a embarcaciones de mayores tonelajes, y con ello mayor extracción de minerales; y por otra parte, el inicio de la explotación del yacimiento de Hierro de Huantemé de la minera Santa Bárbara. Minera que en el periodo de la Unidad Popular (UP), en el año 1971, fue expropiada para formar la Compañía de Acero del Pacífico (CAP). En 1960, la Empresa Nacional de Electricidad S.A (ENDESA), instaló en la Isla Guacolda la primera planta generadora de electricidad termoeléctrica a base de carboncillo como combustible, siendo un hito significativo para la comunidad huasquina, pues la empresa electrificó a todo el pueblo. Lugar, donde 32 años más adelante se instalaría la actual termoeléctrica Guacolda (de la empresa transnacional Aes Andes, ex-Gener).

A fines del año 1978, la empresa McKee puso en marcha la Planta de Pellets de la Compañía de Acero del Pacífico (CAP), en la misma fecha también estaba construido

\footnotetext{
39 Paola Bolados y Alejandra Sánchez, "Una ecología política feminista en construcción: El caso de las Mujeres de zonas de sacrificio en resistencia, Región de Valparaíso, Chile," Psicoperspectivas 16, no. 2 (Junio 2017): p. 36, doi:10.5027/psicoperspectivas-vol16-issue2-fulltext-977

40 Augusto Millán, Historia de la minería del hierro en Chile (Santiago de Chile, Editorial Universitaria 1999), p. 110-130.
} 
el Puerto Guacolda II, con fondos estatales. Luego, en 1981, la CAP fue privatizada pasando a ser el holding Compañía Minera del Pacifico (CMP). En abril del año 1992, inició sus operaciones la Central termoeléctrica Guacolda en la ex Isla Guacolda de la comuna de Huasco, con el propósito de abastecer de suministro eléctrico a las principales mineras del norte del país, aportando al Sistema Interconectado Central (SIC). Durante el mismo año, también se estableció el primer recurso de protección contra la Compañía Minera del Pacífico (CMP), presentada por un grupo de olivocultores y buzos de la bahía de Chapaco. Dicho recurso fue ganado por la comunidad, y con esto se comenzó a exigir que la CMP limitara el material sedimentable y fierro del material particulado, y al mismo tiempo sentó un precedente jurídico para la historia de la justicia ambiental de la comuna de Huasco y Chile. Pese a las diversas manifestaciones tanto jurídicas como sociales de la comunidad, en 1995 comenzó a funcionar la primera unidad de "Guacolda I", de 152 MW. Un año después, en 1996 la central termoeléctrica Guacolda construyó una segunda unidad que aporta 152 MW adicionales al Sistema Interconectado CentralSIC, sumando 304 MW.

El 2006 un estudio reveló exceso de níquel en orina de niños y niñas de 7 a 8 años en Huasco y otras ciudades cercanas a megafuentes contaminantes. ${ }^{41}$ Este hecho impulsó la organización de un grupo de madres y padres, y sobre todo mujeres, organizándose en lo que después se nombraría como Brigada S.O.S Huasco. Mientras el año 2005 se aprobó un proyecto que contemplaba la construcción de un complejo industrial destinado a la crianza de cerdos. A comienzos del año 2011, comenzaron a llegar los primeros porcinos a la comuna de Freirina, y con ello comenzaron a emanar los primeros malos olores percibidos por la comunidad, quienes se organizaron en una lucha social, que significó el despliegue de diversas estrategias comunitarias, como la realización de asambleas locales y provinciales, cierre de carreteras, comunicados y petitorios al Estado de Chile, surgiendo el Movimiento Socioambiental del Valle del Huasco.

\footnotetext{
41 Verónica Iglesias, Soledad Burgos, Nella Marchetti, Claudio Silva y Paulina Pino, "Nivel de níquel urinario en niños residentes en ciudades cercanas a megafuentes," Rev. méd. Chile, no.136 (Agosto, 2008): p. 1039-1046, doi: http://dx.doi.org/10.4067/S003498872008000800013.
} 
El año 2009 entró en funcionamiento la unidad III de la termoeléctrica Guacolda, y se aprobó la unidad IV; y a fines del mismo año, también se ingresó al Sistema de Evaluación de Impacto Ambiental (SEIA) la evaluación de la unidad V. Durante el año 2010, producto de los altos niveles de material particulado (PM10) que superó la norma en un 80\% del máximo permitido, el Servicio Agrícola y Ganadero SAG, y el Servicio de Salud de Atacama, solicitaron a la Comisión Regional del Medio Ambiente (COREMA) que Huasco fuese declarada como Zona Latente por contaminación. No obstante, esta solicitud no es aceptada, y ese mismo año se aprobó la construcción de la unidad V, así se establece la termoeléctrica Guacolda con 5 unidades como la más grande de Chile con 760 MW.

Luego de diversas manifestaciones públicas y presiones en espacios institucionales, la comuna de Huasco fue declarada como zona de latencia el año 2011; y en diciembre del año 2012, la empresa Agrosuper anunció que cerrarían indefinidamente la planta procesadora de cerdos en Freirina. Durante el año 2019, el Movimiento Socioambiental del Valle del Huasco, también siguió una vía legal, mediante la interposición de un recurso de protección a la Corte Suprema para frenar los sondajes de exploración del proyecto minero Nueva Unión en la ladera del río Huasco en el sector de Maitencillo, acompañado de acciones de cortes de rutas bajo el lema: "De cordillera a Mar, el río Huasco hay que salvar". Recurso que fue acogido, en diciembre del mismo año.

Más al sur de Huasco, en la Región de Valparaíso- zona central de Chile, se emplaza la Bahía de Quintero, la cual experimenta una inflexión significativa a partir de la instalación de la termoeléctrica Chilgener el año 1956 y la fundición y refinería de la Empresa Nacional de Minería (ENAMI) el año 1964. Este proyecto se consolidó aún más durante la dictadura (1973-1989), donde en particular la Empresa Nacional de Minería fue ocupada como un espacio estratégico para la fundición del oro y en la cual, los operarios mineros fueron controlados fuertemente por los militares. Las faenas se iniciaron en 1964 con la fundición de cobre y dos años después la refinería 
electrolítica con el tratamiento de metales como el cobre, el oro y la plata. ${ }^{42} \mathrm{Si}$ bien en un comienzo el Parque Industrial tiene estas dos empresas, en la actualidad existen alrededor de 19 empresas, entre las cuales destacan tres asociadas a hidrocarburos como la Empresa Nacional del Petróleo (ENAP), la Compañía de Petróleos de Chile (COPEC) y SHELL, empresas de gas como Gasmar, GNL, y químicas como Oxiquim, la fundición y refinería de la ex ENAMI que desde el 2004 pasa a ser de la Corporación Nacional del Cobre (CODELCO) y las 4 termoeléctricas a carbón de AES Gener, más una termoeléctrica a gas de Enel. Aunque suelen pasar desapercibidas, también se instala la empresa de Cemento Bío Bío y la empresa de Asfalto. Por último, la empresa Puerto Ventanas como proveedor de servicios y actividades portuarias arrienda sectores del puerto para actividades de otras empresas como Minera Angloamerican.

Documentos gubernamentales muestran que a finales de la década de los años 70 el sector agrícola daba a conocer la afectación de la producción de los campos, otrora la principal actividad de Puchuncaví. Conocida por sus guisantes (arvejas), no obstante la tierra se comenzó a acidificar generando mermas progresivas en la producción. En la década de los años 80, la revista de la Agencia de Prensa de Servicios Internacionales (APSI), dio cuenta de este daño refiriéndose a la "lluvia ácida" como la causa principal y en una nota aparte, relata la historia de "los hombrecitos verdes". Quienes fueron trabajadores que estuvieron en la construcción e inicios de ENAMI, y tras la muerte de varios de ellos y la constatación de graves enfermedades derivadas por su trabajo, durante el año 2006, se lograron articular como la Asociación de Ex Funcionarios de ENAMI (ASOREFEN). En esos años se conoció también la denuncia de parte de vecinas del sector, quienes ven con preocupación la situación de su comuna y los problemas de salud en sus familias. La situación trascendió y por ello se estableció en la Bahía compartida por las comunas de Puchuncaví y Quintero, el primer Plan de Descontaminación el año 1992, un año antes de su declaración como Zona Saturada.

Bajo las expectativas de la nueva legislación ambiental el año 1994, la bahía vio crecer su complejo industrial de dos a 19 empresas. El 2008 se conoció uno de los 
derrames más importantes producto del volcamiento de sustancias químicas de más de 300 toneladas, luego entre el 2014 y 2016 se produjeron 3 derrames asociados a descarga de hidrocarburos los cuales sumaron casi 200 litros más. Estos hechos junto a las décadas de utilización del mar para la eliminación de los residuos de las empresas, dañaron la vida marina afectando a la economía de diversos sindicatos de pescadores. Estos prontamente se vieron forzados a incorporarse a las empresas a fin de recibir ingresos, instalando relaciones de dependencia progresiva con la empresa y transformándose en los que limpian el carbón y encargados de apoyar las limpiezas ante los derrames producidos. En ese período las organizaciones del territorio se organizan frente a la construcción de la cuarta termoeléctrica Campiche, la cual se instaló en una zona de amortiguación que a través de un cambio de uso de suelo, logró tener autorización para su construcción. Esto marcó otro hito de la conflictividad local en la medida que reveló la incidencia de las corporaciones trasnacionales como Aes Gener en las decisiones nacionales y regionales bajo una total exclusión de los actores locales.

Paralelamente, entre el 2011 y 2012, también se produjo la intoxicación de 47 estudiantes y de algunos docentes de la Escuela la Greda, y la aparición de diversos estudios asociados a la contaminación de los recursos marinos activaron la emergencia ambiental. En ese contexto, la Escuela La Greda fue removida $2 \mathrm{~km}$ de su emplazamiento original. Este hecho manifestó la falta de control y la escasa regulación de la actividad industrial por parte del Estado, pues se identificó que entre las más de 19 empresas emplazadas en el área industrial no quedaba claro cuáles tenían o no resolución de calificación ambiental y sanitaria ${ }^{43}$. Finalmente, la intoxicación de más de 700 personas en agosto del 2018 resurgió las tensiones asociadas a las responsabilidades del Estado y las empresas respecto al daño ambiental acumulado. En particular, se dieron cuenta de las limitaciones legales del Estado y las negligencias técnicas de las empresas, las cuales no lograron esclarecer el origen de los episodios. Organizaciones del territorio y ONGs ambientalistas denunciaron al Estado por el daño a la población y por poner en riesgo la salud de las

43 Fundación TERRAM, "Infografía: La evaluación ambiental en Quintero y Puchuncavi," TERRAM (2020), https://www.terram.cl/2020/08/infografia-la-evaluacion-ambiental-en-quintero-y-puchuncavi/ 
personas, obteniendo un fallo inédito de la Corte Suprema que ratificó la responsabilidad del Estado y las empresas y les obligó a realizar varias medidas de reparación. Actualmente las organizaciones siguen demandando respuestas denunciando que no se ha cumplido el fallo, mientras servicios del Estado han insistido en señalar que se han tomado las medidas, incluso planteando que la situación ambiental de la zona ha mejorado.

Más al sur, en la región del Bío Bío, la historia ambiental de Coronel comienza con la minería de carbón en Schwager (Coronel) desde 1855. El daño ambiental generado por las mineras carboníferas fueron diversas, entre estas se encuentra el relleno de valles y humedales, levantamiento de cimas con residuos, tala de bosque nativo en la cordillera de Nahuelbuta, plantación forestal, "quema intensiva y extensiva de carbón como combustible industrial y domiciliario, vertidos de residuos al mar, lavado de carbón en los esteros, entre otros" ${ }^{\prime 4}$.

El escenario industrial de Coronel, antes de la llegada del neoliberalismo, estaba compuesto principalmente por las minerías a Carbón y de la Termoeléctrica Bocamina I (128 MW), instalada en el 1969 a modo de utilizar el carbón explotado en las minerías en un contexto de cesantía y crisis económica. En la década de los años 90, luego del cierre de las mineras a carbón, se comienza a configurar una rápida instalación industrial en la zona norte de la comuna y el borde costero, entre estas industrias se encuentra el puerto de Coronel, industrias pesqueras instaladas en el cordón Industrial Escuadrón ${ }^{45}$ y en la bahía costera, cerca del casco histórico de la comuna.

Las industrias ubicadas en el borde costero, principalmente el Puerto de Coronel, han fragmentado la histórica relación de la comunidad con el mar, reemplazando el libre acceso por un gran cordón de murallas grises. Además, la instalación portuaria en Coronel ha ocasionado una gran contaminación ambiental, como los "dragados del fondo marino, vertido de aguas lastre, acopio y movimiento de contenedores, ruidos molestos, aumento de los flujos de vehículos de carga por la

\footnotetext{
44 Ministerio del Medio Ambiente, Programa para la recuperación ambiental y social de Coronel (Santiago de Chile: Gobierno de Chile, 2018): p. 54, https://pras.mma.gob.cl/wp-content/uploads/2019/11/PRAS-Coronel.pdf

45 Ministerio del Medio Ambiente, Programa para la recuperación: 55.
} 
ciudad, entre otros". ${ }^{46} \mathrm{Al} 2014$ se estimaba que la superficie industrial constituida por los Parques Industriales Escuadrón 1 y 2 y el Parque Industrial de Coronel, eran de 730 hectáreas de superficie, considerándose unos de los polos industriales más grande de Chile ${ }^{47}$. El año 2006, Coronel (y el Gran Concepción) fue declarada zona de latencia por contaminación de material particulado respirable MP10. ${ }^{48}$ Pese a esta declaración, dos años después se anuncia la instalación de dos nuevas unidades termoeléctricas a carbón, que con el tiempo agravará aún más la contaminación ambiental, otorgando posteriormente la denominación de "Zona de sacrificio", luego de que la comuna fuera declarada como zona saturada, a través del Decreto Supremo Nº15 del año 2015.

Durante el 2012 cuando comienza el funcionamiento de la termoeléctrica Santa María de Colbún y la segunda unidad de Bocamina, estalla los primeros movimientos contra los impactos ambientales de estas industrias a carbón. Durante este periodo se comienza a percibir la contaminación en el aire y la contaminación acústica, es por esto que la población La colonia, rodeada en ese momento de un vertedero de cenizas y de la termoeléctrica Bocamina II, inician una intensa movilización. El evidente daño de la termoeléctrica en el borde costero significó un impacto directo en la fuente laboral de pescadores y recolectores de orilla, por esto levantan una fuerte lucha contra la termoeléctrica Bocamina basada en demandas ante el tribunal ambiental de Valdivia. Lucha que fue protagonizada por un mujer dedicada a la recolección de algas de la zona, quien se enfrentó de manera directa contra Bocamina.

Un estudio realizado el 2016, encontró que 6,3\% de 285 niños/as, tenían altos niveles de metales pesados en la sangre. A principios del 2018, se halló una alta concentración de metales pesados en la sangre en 21 personas vinculadas a la Escuela Rosa Medel. En respuesta al evidente daño a la salud de la comunidad, comienza a

\footnotetext{
46 Municipalidad de Coronel, Propuesta Ambiental de la Municipalidad de Coronel, en el contexto del Programa de Recuperación de Territorios Ambientalmente Vulnerables del Ministerio del Medio Ambiente, en adelante Programa de Recuperación Ambiental y Social (PRAS) y Consejo de Recuperación Ambiental y Social (CRAS) de Coronel. (Coronel: Observatorio Ecológico de Coronel, 2015): 4, https://www.terram.cl/carbon/2015/11/propuesta-ambiental-de-la-municipalidad-de-coronel/

47 ECoronel.com, "Actividad Industrial," Observatorio Ecológico de Coronel, last accessed Sep 03, 2021, https://www.ecoronel.cl/atlas-ambiental-de-coronel/medio-humano/aspectos-socioeconomicos/base-economica-productiva/actividadindustrial/

48 Mma.gob.cl, "Ministerio de Medio Ambiente declara Zona Saturada a Gran Concepción y elaborará plan de descontaminación," Ministerio del Medio Ambiente, Julio 15, 2015, https://mma.gob.cl/ministerio-de-medio-ambiente-declara-zona-saturada-a-granconcepcion-y-elaborara-plan-de-descontaminacion/
} 
gestarse una resistencia por parte de distintos sectores, creándose espacios de organización ambiental a nivel comunal y poblacional. Actualmente, el Nuevo Plan Regulador Metropolitano de Concepción ha reactivado la conflictividad de la zona, en tanto permite crear nuevos sectores de bodega, ampliar rutas de comercio, crear infraestructuras inmobiliarias en humedales, lagunas y esteros, e ingresar más industrias molestas y peligrosas al sector industrial de Coronel.

\section{DE ZONA DE SACRIFICIO A TERRITORIOS EN RECUPERACIÓN. ESTRATEGIAS DE CONSTRUCCIÓN DE MEMORIA Y RECUPERACIÓN SOCIAL Y AMBIENTAL}

Las resistencias y luchas por la justicia ambiental en zonas de sacrificio en el último período, ha traído una reflexión colectiva de lo que significa el término. Frente a esto, comunidades y organizaciones intentan mostrar sus luchas como caminos de recuperación socioambiental. El término se construye desde experiencias de reapropiación del territorio a través de sitios de biodiversidad y de memoria que pasan a constituirse en estrategias para fortalecer la organización social. El término recuperación, se propone como una parte del territorio que la noción de zona de sacrificio invisibiliza, en tanto remarca las dimensiones de violencia y destrucción y no permite visualizar los elementos regenerativos del territorio.

Organizaciones han enfatizado la protección de humedales, acantilados, ríos y la biodiversidad como parte de la recuperación social, en tanto sin estos espacios y hábitat la vida colectiva resulta insostenible. Frente a esto emergen experiencias que buscan desnaturalizar la colonización de la naturaleza en los territorios a través de estrategias de asegurar el acceso a estos bienes naturales comunes.

UN RÍO DE MEMORIAS: EXPERIENCIAS DE RECUPERACIÓN SOCIOAMBIENTAL EN HUASCO.

Huasco como una comuna inmersa en uno de los desiertos más áridos del mundo, el agua y todos sus afluentes se configuran en un eje central de la recuperación socio-ambiental. El humedal Estuario del Río Huasco, que se ubica en la playa grande del puerto de Huasco, forma parte de las 25 zonas "Hot spots" con mayor diversidad biológica del mundo donde se destaca una gran gama de especies de flora y fauna, caracterizada por su alto endemismo. Se han registrado más de 180 especies, 
siendo uno de los humedales más significativos del país, con una gran biodiversidad. A diferencia de Coronel, aún no ha germinado algún colectivo social que centre sus objetivos en la defensa de los humedales y su protección, tratándose más bien de esfuerzos individuales de personas autónomas e instituciones del Estado que han propiciado una aún incipiente visibilización del humedal a través de distintos medios y estrategias como: jornadas educativas en terreno, birdwatching, fotografía, dibujo. Todo esto sumado a la presentación durante el año 2005 del informe de Solicitud para la creación de Santuario de la Naturaleza "Humedal Estuario del Río Huasco" por parte de la Dirección Regional de la CONAMA y la Secretaría Técnica Comité Operativo Regional de Biodiversidad, petición que aún está en trámite.

Con más de 3 décadas de organización comunitaria, se ha formado una mirada de protección sobre la cuenca del Valle del Huasco en su conjunto, siendo clave la articulación del Movimiento Socioambiental del Valle del Huasco en torno a la defensa del Río , de acuerdo a la voz de una activista de la comuna de Freirina: "El río es la columna vertebral de la cuenca del valle del Huasco, es nuestro corazón, que nutre de vida a todas las especies que compartimos en este valle". ${ }^{49}$

A pesar que los esfuerzos se centran en la recuperación ambiental del territorio, también se visualizan experiencias de recuperación social, de la mano de mejoras de espacios urbanos. Como la experiencia realizada por Luis Alberto Triviño Charlin y Lorenzo Triviño González, padre e hijo, desde el año 2001 cimentaron los orígenes del actual Parque San Francisco, conocido por la comunidad como "Trivilandia". Recuperando la quebrada de la conchería que estaba siendo utilizada como un vertedero de escombros. El parque que se inauguró en octubre del año 2003, está ubicado en el sector de las concherías de la comuna de Huasco, inspirado en formar un espacio digno para que los y las niñas del sector jugaran, y en la naturaleza del desierto florido. Sus vistas al mar, permiten contemplar el contraste de la naturaleza con las chimeneas de la termoeléctrica Guacolda y CPM, con una distancia lineal de 2,57 km entre el parque y el complejo industrial de la termoeléctrica Guacolda.

49 Entrevista, comuna de Freirina, febrero, 2021. 
Un papel relevante en la recuperación de Huasco ha sido el trabajo artístico de la familia Triviño. En ellos, trabajos audiovisuales como los de Material Particulado y otras expresiones artísticas creadas y realizadas por Sebastían Triviño, intentan mostrar al arte como camino de recuperación y regeneración social:

El año 2015 realicé el primer registro fotográfico, con mi abuela que hicieron una técnica vitral, y yo le hice los diseños a partir de 30 flores del desierto. Después, vino el desafío del 2017 de realizar un catálogo de 100 especies, fueran endémicas o no. Ahí me encontré con las dificultades de encontrar datos, comprender las dificultades de la terminología botánica, y este proceso no ha sido solo mío, ha sido gracias a personas que me han contribuido en este proceso, esto es la vida misma haciéndome clases, y también mi interés de construir amistades, y de construir y compartir estas experiencias. Fue un vamos a explorar un lugar y ver qué hay, fue un recorrer y fue apareciendo esta información. ${ }^{50}$

Las organizaciones del territorio, en esta búsqueda, por impactar en vecinos y vecinas, ajenos a la sensibilidad de defensa del territorio, han realizado diversos encuentros en pos de reconstruir la memoria comunitaria previa a la instalación de los complejos industriales, y la unión de la Isla Guacolda al continente. Como por ejemplo, jornadas educativas, y la reciente intervención del 29 de agosto del año 2021, actividad que se denominó "Reconstruyendo nuestra memoria, perfomance comunitaria”, y consistió en la recreación de una antigua procesión que se realizaba en Huasco previo a la unión de la isla al continente, rito que reunía a las familias en la isla y se trasladaban productos agrícolas del interior del valle para ser compartidos en dicha jornada. Actividad que se recreó contando con la participación activa de pescadores, docentes, madres, jóvenes, adultos mayores, y diversos actores sociales de la comuna y de la cuenca del Valle del Huasco.

\section{AL BORDE DEL ACANTILADO SURGE SALVEMOS QUIRILLUCA}

Quirilluca es un sector ubicado en la caleta de Horcón, parte de la comuna de Puchuncaví. Los acantilados de Quirilluca se transformaron en los últimos años en un sitio priorizado por la comunidad para la recuperación social y ambiental. En medio de permanentes hitos de contaminación la comunidad de Horcón, ha liderado una resistencia asociada a la protección de los Acantilados de Quirilluca. Dentro de este espacio de biodiversidad y de uso comunitario para actividades recreativas, se

50 Entrevista, comuna de Huasco, abril 2021. 
pretende emplazar el proyecto inmobiliario Maratué, el cual implica la construcción de más de 14 mil viviendas, lo que triplica la población actual de Puchuncaví. Este pretende instalarse en un territorio en el que el 31\% de sus habitantes no tiene acceso a servicios básicos de agua potable y alcantarillado, lugar que ha sido declarado con escasez hídrica el 2020.

Como oposición al proyecto Maratué el año 2017 comienza un proceso de organización y estrategias de defensa del territorio bajo el lema de 'Me empelota Maratué. El movimiento incluye información por redes sociales, convocatorias en espacios públicos y sedes de organizaciones, elaboración de materiales divulgativos, caravanas, pasacalles y procesión de cuerpos pintados. A partir de esta experiencia de organización y resistencia que defiende el patrimonio natural y cultural, se configuran ejes que buscan la protección del territorio, de la historia, la memoria y la identidad. Así lo mencionan sus habitantes, quienes consideran el proyecto Maratué como una amenaza a su identidad.

Me duele esa palabra: Maratué. Porque ellos cambian hasta nuestra identidad. El lugar es conocido por nuestros antepasados, por nuestros abuelos, como Quirilluca, y vienen y lo cambian de la noche a la mañana. Igual es parte de nuestra cultura que está en juego, en riesgo. ${ }^{51}$

Tras un tiempo de movilización, la organización cambia de nombre a Salvemos Quirilluca, todo esto con el motivo de visibilizar los valores ecológicos del lugar y fomentar el involucramiento informado de la comunidad en la actualización del Plan Regulador Comunal. Aprovechan sus primeras instancias de participación ciudadana para conseguir reunir firmas solicitando que el área ya propuesta Santuario sea efectivamente protegida a través del instrumento de planificación comunal.

La gente que tiene más dinero trata de quedarse siempre al lado del mar, adueñarse de los lugares más bellos, que deberían ser protegidos y preservados para toda la gente, no que porque tu tienes dinero tienes el privilegio de dañar la naturaleza. ${ }^{52}$

Después de la intensa movilización, las firmas reunidas y las observaciones realizadas contra el proyecto Maratué, este es aprobado el 2019 sin ninguna oposición de parte del sector público. Esta situación de injusticia da origen a un camino de judicialización

51 Jl. Radio Colo Colo, Abril, 2020

52.Jl. Radio Colo Colo, Abril, 2020 
contra el proyecto. Esta experiencia de resistencia, que surge en un escenario de injusticia ambiental y de sacrificio, habla de un territorio vivo y con capacidad de organización que pone en práctica los recursos y capacidades de sus habitantes con el objetivo de proteger el territorio de la comunidad. Pescadores y artesanos del sector, han dedicado tres años de una intensa lucha para evitar la destrucción del último pulmón verde que está quedando en una comuna catalogada como "zona de sacrificio".

\section{CAMino A la PROTECCiÓn del Humedal Boca MAUlE}

En la comuna de Coronel se encuentra el humedal Boca Maule, que se destaca por su alto valor natural, histórico y cultural, razón por la cual el 2012 fue declarada como zona típica por el Consejo de Monumento Nacionales. ${ }^{53}$ El caso de resistencia que se ha desarrollado en el humedal Boca Maule responde a un deterioro que se ha acentuado con la situación de sacrificio que vive el territorio de Coronel. Quienes habitan cerca del humedal han crecido vinculándose a este ecosistema, siendo testigos de la transformación y de las amenazas del mismo. Entre las amenazas y deterioro al humedal se encuentran los rellenos, los micro basurales, la contaminación producida por la minera de carbón ubicada en la desembocadura y los futuros proyectos viales que pretenden construirse cerca del humedal. Todo esto sumado a la amenaza de otros proyectos viales a los cuerpos de agua (esteros y lagunas) que componen el humedal, presentes en la nueva actualización del Plan Regulador Metropolitano de Concepción.

La actual desprotección legal del humedal, dio a lugar que a mediados del 2020 se rellenara una gran parte del sector por parte de un particular. Este hecho dio origen a la conformación del colectivo Salvemos el Humedal Boca Maule, quienes denunciaron el relleno ilegal desproporcionado que se estaba realizando en el sector norte del Humedal. Si bien se pudo detener el relleno de gran magnitud, este no se ha frenado en su totalidad. Después de diversos esfuerzos por parte de la comunidad, y

\footnotetext{
53 Monumentos.gob.cl, "Sector Maule Schwager," Consejo de Monumentos Nacionales de Chile, last accessed sept. 2, 2021, https://www.monumentos.gob.cl/monumentos/zonas-tipicas/sector-maule-schwager
} 
luego del arduo trabajo realizado por el colectivo, el 15 de noviembre de 2021 se decreta el Humedal Boca Maule como humedal urbano bajo la ley 19.300.

Para quienes conforman el Colectivo, la defensa del Humedal Boca Maule se traduce en una lucha interminable, principalmente porque el reconocimiento de humedal urbano (que entrega protección legal) no asegura una total protección al humedal, puesto que la organización y la unión comunal es clave para la defensa del humedal y de los territorios. La recuperación de los espacios por la comunidad permite generar una protección que surge desde los mismos habitantes, quienes se hacen parte del lugar donde viven y lo defienden como su propio hogar. La manera para no estar inmovilizados frente a las amenazas que ocurren en el humedal es organizarse, y esta se potencia tomando conciencia del valor ecosistémico y natural del Humedal Boca Maule:

[...] como ya somos una denominada zona de sacrificio, siento yo que por parte del poder empresarial le está dando lo mismo la calidad de vida de las personas, solamente están como queriendo instalar más y más industrias, por eso la resistencia de nosotros. Si la población no se organiza, siempre nos van a pasar por encima, en lo industrial, lo productivo, el modelo extractivista, todo esto va por encima de la naturaleza. ${ }^{54}$

El colectivo Boca Maule ha iniciado un proceso de recuperación del humedal que está fuertemente ligado a la concientización y a la organización comunal, lo que se traduce en la motivación y preocupación de defender el humedal por parte de los mismos vecinos y vecinas del sector y de quienes se sienten identificado con el humedal y no viven cerca de él. Una joven mujer habitante del sector de Maule, menciona que la organización es la vía para defender la naturaleza y el territorio.

No podemos seguir permitiendo que se nos pase por alto, estar como aturdido durmiendo, viendo cómo la industria se apodera del territorio, y nos quitan el territorio, nos quitan el acceso a la playa, y nos quitan el agua limpia, y nos quitan el aire limpio, no podemos seguir de brazos cruzados. [...] mientras los vecinos y vecinas estén preocupados por lo que pasa en el humedal, y estén en el humedal, al humedal nada malo le va a pasar..$^{55}$

En este sentido, la organización de la comunidad es clave en la defensa de los territorios compartidos, y así lo han evidenciado el colectivo Salvemos el Humedal Boca Maule, quienes han demostrado que, a través de la organización y la difusión de

54 Entrevista a miembro del Colectivo Salvemos el Humedal Boca Maule, Enero de 2021.

55 Entrevista Miembro del Colectivo Salvemos el Humedal Boca Maule, Enero 2021. 
los daños al humedal, se puede generar presión para exigir respuestas a las autoridades ambientales tanto a nivel comunal como regional. Esta experiencia de recuperación, que surge en un contexto de injusticia ambiental y sacrificio, no sólo ha beneficiado al humedal, sino que ha reconstruido y fortalecido el tejido social y comunitario en torno al ecosistema. A través de la recuperación de los espacios comunes el humedal Boca Maule deja de ser un espacio "vacío" y se convierte en un territorio con entramados vivos (entre especies humanas y no humanas), que se vincula con los recuerdos, la memoria y la historia de quienes habitan este lugar.

\section{CONCLUSIONES}

En este artículo hemos planteado una lectura crítica para comprender las relaciones entre zonas de sacrificio y justicia ambiental. Hemos profundizado las miradas respecto a esta definición en un contexto de prácticas económicas extractivistas y legislaciones débiles que favorecen la idea de una destinación a sacrificar territorios para la actividad industrial contaminante. Sin embargo, mostrando su recorrido en el movimiento de justicia ambiental norteamericano y latinoamericano, hemos intentado de plantear novedosas y heterogéneas perspectivas propuestas por los trabajos que emergen desde el caso chileno.

En particular, hemos intentado mostrar a partir de tres casos del norte, centro y sur chileno, los procesos históricos que han facilitado la construcción de estas comunidades como zonas de sacrificio, así como sus movilizaciones y resistencia para transformarlas en territorios de recuperación social y ambiental. En esto relevamos el protagonismo de las organizaciones que amplían las miradas jurídicas de la justicia ambiental, así como exceden las perspectivas institucionales para proponer creativas formas de descolonizar la naturaleza y recuperarla bajo una mirada que reconoce la interdependencia entre lo social y ambiental.

Una aproximación a las historias ambientales desde los territorios, consideramos contribuye de manera central a mostrar las condiciones históricas bajo las cuales se construyen estas zonas como zonas de sacrificio, así como las 
condiciones históricas de sus recuperaciones, desde sus habitantes y sus propuestas colectivas de resistencias.

Las luchas por justicia ambiental en las denominadas zonas de sacrificio, plantean formas nuevas de enfrentar las desigualdades socioambientales. Las acciones colectivas centradas en la judicialización de los conflictos, ahora incorporan estrategias de recuperación de los bienes naturales a través de la protección de espacios y sitios de biodiversidad y memoria que son y han sido relevantes en las historias ambientales de los territorios degradados por una economía depredadora. Estas experiencias revelan que la recuperación es social y ambiental simultáneamente, reafirmando la interdependencia entre la naturaleza y la cultura.

Las historias ambientales de territorios como Huasco, Puchuncaví, Quintero y Coronel dan cuenta las lógicas de apropiación y colonización de los imaginarios extractivistas que buscan imponerse como única forma de valoración ecológica y ambiental. No obstante, aún en contexto de extremas desigualdades, las comunidades resisten a través de acciones de salvación de humedales, acantilados, flores endémicas, recuperando espacios públicos, performances, etc; que intentan modificar la historia de degradación en historias de recuperación.

Para esta desnaturalización de la naturaleza explotable, el concepto de zonas de sacrificio ha sido central en la problematización de las desiguales cargas ambientales sufridas en algunos territorios. Del reconocimiento como zonas de sacrificio, las comunidades y organizaciones han pasado a centrar su interés en la recuperación ambiental y social bajo los principios de la justicia ambiental. Este camino incorpora prácticas de autogestión e intervenciones artísticas que permiten reconstruir formas de lucha por la justicia ambiental en Chile.

\section{Agradecimientos}

Este artículo es parte del Proyecto de Investigación Fondecyt Regular 1191269 titulado "De Zonas de Sacrificio a Zonas de Recuperación Socioambiental: construcción participativa de criterios de gobernanza ambiental y bienestar en las 
bahías-puerto de Huasco, Puchuncaví-Quintero y Coronel, Chile", el cual se realizó con el financiado de la Agencia Nacional de Investigación y Desarrollo.

\section{REFERENCIAS}

Acselrad, Henry. Conflito social e meio ambiente no estado do Rio de Janeiro. Sao Paulo: Editora Relume Dumará, 2004.

Agoglia, Ofelia. "Los aportes de la ecología política latinoamericana a la corriente ambiental crítica." América Crítica 2, no. 2 (Diciembre 2018): 111-122. doi:10.13125/americacritica/3306

Alimonda, Hector. "La colonialidad de la naturaleza. Una aproximación a la Ecología Política Latinoamericana", En La Naturaleza Colonizada, coord. Hector Alimonda, 2158, Buenos Aires: Clacso, $2011 . \quad$ doi: http://biblioteca.clacso.edu.ar/ar/libros/grupos/alimonda.pdf

Arias, Juan David. "Ecología Política: Desafíos de la Contabilidad frente a la Justicia Ambiental." En-contexto, no. 6 (febrero 2017): 303-326.

Arriaga, Alicia y Mercedes Pardo . "Justicia Ambiental. El estado de la cuestión." Revista Internacional de Sociología 69, no. 3 (Diciembre 2011): 627-648. doi: 10.3989/ris.2009.12.210

Baver, Sherrie. "Institutions of Environmental Democracy and Environmental Justice: The Case of Chile." CUNY Graduate Center, no. 554 (April, 2017): 1-30.

Bolados, Paola y Alejandra Sánchez . "Una ecología política feminista en construcción: El caso de las Mujeres de zonas de sacrificio en resistencia, Región de Valparaíso, Chile." Psicoperspectivas 16, no. 2 (Junio 2017): 33-42. doi:10.5027/psicoperspectivasvol 16-issue2-fulltext-977

Bolados, Paola y Bárbara Jerez. "Genealogía de un desastre: la historia ambiental de una zona de sacrificio en la bahía de Quintero, Chile." en Pensamento crítico latinoamericano. Reflexoes sobre políticas e fronteras, (Belém, Annablume Ediciones, 2019): 149-150.

Bullard, Robert. Dumping in Dixie: Race, class, and environmental quality. 3 ed. New York, NY: Routledge, 2018

ECoronel.com. "Actividad Industrial." Observatorio Ecológico de Coronel, last accessed Sept. 03, 2021. https://www.ecoronel.cl/atlas-ambiental-decoronel/medio-humano/aspectos-socioeconomicos/base-economicaproductiva/actividad-industrial/ 
Ejnet.org Editors. "Principles of Environmental Justice." April 6, 1996. http://www.ejnet.org/ej/principles.html

Escobar, Arturo. "Ecología Política de la globalidad y la diferencia." En La Naturaleza Colonizada, coord. Hector Alimonda, 61-92. Argentina: CLACSO, 2011. doi: http://biblioteca.clacso.edu.ar/ar/libros/grupos/alimonda.pdf

Folchi, Mauricio. "Environmentalism of the Poor: Environmental Conflicts and Environmental Justice." En Social-ecological Systems of Latin America: Complexities and Challenges, ed. Luisa Delgado y Victor Marín, Switzerland: Springer Nature, 2019. doi: https://doi.org/10.1007/978-3-030-28452-7

Folchi, Manuel. "Zonas de sacrificio: Distinto origen, mismo destino (Texto basado en entrevista realizada al experto)." En Los territorios que habita(re)mos: ¿Qué futuro existe para las zonas de sacrificio?, editado por Enrique Aliste et al., Position Paper, No. 1, e(Santiago, Chile:Universidad de Chile, 2020), 29- 35.

Gudynas, Eduardo. Extractivismos. Ecología y política de un modo de entender el desarrollo y la naturaleza. Perú: CLAES, 2015.

Leff, Enrique. "La ecología política en América Latina: Un campo en construcción." Sociedade e Estado 18, no. 1/2 (Sept. 2003): 17-40.

Lerner, Steve. Sacrifice Zones: The Front Lines of Toxic Chemical Exposure in the United States. Cambrige-Massachusets: MIT Press, 2010.

Martínez Alier, Joan. "Ecologismo de los Pobres." Ecologistas en Acción. Septiembre 1, 2015. https://www.ecologistasenaccion.org/7976/el-ecologismo-de-los-pobres/.

Merlisnky, Gabriela. Política, derechos y justicia ambiental: El conflicto del Riachuelo. Argentina: Fondo Cultura Económica, 2013.

Merlinsky, Gabriela. "Justicia Ambiental y políticas de reconocimiento en Buenos Aires." Perfiles Latinoamericanos 26, no. 51 (Enero 2018): 241-263. doi:10.18504/pl2651010-201

Ministerio del Medio Ambiente. Programa para la recuperación ambiental y social de Coronel. Santiago de Chile: Gobierno de Chile, 2018. https://pras.mma.gob.cl/wpcontent/uploads/2019/11/PRAS-Coronel.pdf

Mma.gob.cl. "Ministerio de Medio Ambiente declara Zona Saturada a Gran Concepción y elaborará plan de descontaminación." Ministerio del Medio Ambiente. Julio 15, 2015. https://mma.gob.cl/ministerio-de-medio-ambiente-declara-zonasaturada-a-gran-concepcion-y-elaborara-plan-de-descontaminacion /

Monumentos.gob.cl. "Sector Maule Schwager." Consejo de Monumentos Nacionales de Chile. last accessed 2021. https://www.monumentos.gob.cl/monumentos/zonas-tipicas/sector-mauleschwager 
Municipalidad de Coronel. Propuesta Ambiental de la Municipalidad de Coronel, en el contexto del Programa de Recuperación de Territorios Ambientalmente Vulnerables del Ministerio del Medio Ambiente, en adelante Programa de Recuperación Ambiental y Social (PRAS) y Consejo de Recuperación Ambiental y Social (CRAS) de Coronel. Coronel: Observatorio Ecológico de Coronel, 2015. https://www.terram.cl/carbon/2015/11/propuesta-ambiental-de-la-municipalidadde-coronel/

Muñoz, Echart y María del Carmen Villarreal. "Resistencias y alternativas al desarrollo en América Latina y el Caribe: luchas sociales contra el extractivismo." Revista Relaciones Internacionales, no. 39 (Agosto 2018): 141-163. doi:10.15366/relacionesinternaciona-les2018.39.001

Nuñez, Andrés y Enrique Aliste. Geografías imaginarias y el oasis del desarrollo: Cambio climático y la promesa del futuro esplendor. Santiago, LOM, 2020. Ortega, Miquel. "Origen y Evolución del movimiento de la Justicia Ambiental." Ecología política, no. 41 (Junio 18, 2011): 17-24.

Retamal, Alejandro, Pedro Villasana, Felipe Vergara, Juan Mansilla y Germán Moreno. "Zonas de sacrificio en Chile, criterios y condiciones de posibilidad: el caso del Seno del Reloncaví." Revista Notas Históricas y Geográficas, no. 26, (Abril 2021): 95-143.

Schloberg, David. "Reconceiving Environmental Justice: Global Movements And Political Theories." Environmental Politics 13, no. 3 (January 2004): 517-540. doi:0.1080/0964401042000229025

Schlosberg, David. "Justicia ambiental y climática: de la equidad al funcionamiento comunitario." Ecología política, no. 41 (Junio 18, 2011): 25-35.

Svampa, Maristella y Ariel Slipak. "China en América Latina: Del Consenso de los Commodities al Consenso de Beijing." Ensambles 2, no. 3 (Primavera 2015): 34-63.

Tellez, Lida, Leo Name y Céline Veríssimo. "Injusticia ambiental en un contexto industrial: el caso de Villa Hayes (Paraguay) como zona de sacrificio." (paper presentada en XVI Encuentro de Geógrafos de América Latina, La Paz, Bolivia, 2017). http://observatoriogeograficoamericalatina.org.mx/egal16/Procesosambientales/Cli matologia/32.pdf

Valenzuela-Fuentes, Katia, Esteban Alarcón-Barrueto y Robinson Torres-Salinas. "Resistance to Creation: Socio-Environmental Activism" In Chile's "Sacrifice Zones." Sustainability 13, no. 6 (Marzo, 2021). doi: https://doi.org/10.3390/su13063481

Véliz-Burgos, Alex. "Ecología, salud y bienestar humano: miradas desde la Psicología." Revista costarricense de psicología 39, (Abril 2020): 1-2.

Villasana, Pedro, Anita Dörner, Juan Estay, Germán Moreno y Alessandro Sanchez. "Zonas de sacrificio y justicia ambiental en Chile: una mirada crítica desde los 
Objetivos de Desarrollo Sostenible 2030." Historia Ambiental, Latinoamericana y Caribeña 10, no. 3 (Diciembre, 2020): 342-365, doi: 10.32991/2237-2717.2020v10i3.

\title{
History of the Struggles for Environmental Justice in the Sacrifice Zones in Chile
}

\begin{abstract}
In this article we analyze the environmental history of three coastal bays designated as sacrifice zones in Chile. From their stories marked by socio-environmental inequalities and the fight for environmental justice, we observe the process of social and environmental conflict, incorporating the contributions of environmental history, political ecology of extractivism, and critical geography, and we account for the community and organizational strategies that seek to socially and environmentally recover these degraded territories. We conclude that, in this process, the concept of environmental justice acquires less legal and more socio-environmental readings through collective experiences that take as their center the recovery of ecosystems from the community participation and memory.
\end{abstract}

Keywords: Socio-Environmental Inequalities; Environmental Justice; Extractivism; SocioEnvironmental Recovery. 